\title{
Multimodal Microstructure and Mechanical Properties of AZ91 Mg Alloy Prepared by Equal Channel Angular Pressing plus Aging
}

\author{
Zhenquan Yang ${ }^{1}$, Aibin Ma ${ }^{1,2, *}$, Huan Liu ${ }^{1,3}{ }^{\circledR}$, Jiapeng Sun ${ }^{1, *} \mathbb{C}$, Dan Song ${ }^{1}$, Ce Wang ${ }^{1}$, \\ Yuchun Yuan ${ }^{1}$ and Jinghua Jiang ${ }^{1}$ \\ 1 College of Mechanics and Materials, Hohai University, Nanjing 211100, China; \\ yang-zhen-quan@hotmail.com (Z.Y.); liuhuanseu@hhu.edu.cn (H.L.); songdancharls@hhu.edu.cn (D.S.); \\ wangcehhu2013@163.com (C.W.); yychehai@163.com (Y.Y.); jinghua-jiang@hhu.edu.cn (J.J.) \\ 2 Suqian Research Institute, Hohai University, Suqian 223800, China \\ 3 Jiangsu Wujin Stainless Steel Pipe Group Company Limited, Changzhou 213111, China \\ * Correspondence: aibin-ma@hhu.edu.cn (A.M.); sun.jiap@gmail.com (J.S.); Tel.: +86-025-8378-7239 (A.M.)
}

Received: 7 September 2018; Accepted: 25 September 2018; Published: 26 September 2018 updates

\begin{abstract}
Developing cost-effective magnesium alloys with high strength and good ductility is a long-standing challenge for lightweight metals. Here we present a multimodal grain structured AZ91 $\mathrm{Mg}$ alloy with both high strength and good ductility, prepared through a combined processing route of low-pass ECAP with short-time aging. This multimodal grain structure consisted of coarse grains and fine grains modified by heterogeneous precipitates, which resulted from incomplete dynamic recrystallization. This novel microstructure manifested in both superior high strength (tensile strength of $360 \mathrm{MPa}$ ) and good ductility (elongation of $21.2 \%$ ). The high strength was mainly attributed to the synergistic effect of grain refinement, back-stress strengthening, and precipitation strengthening. The favorable ductility, meanwhile, was ascribed to the grain refinement and multimodal grain structure. We believe that our microstructure control strategy could be applicable to magnesium alloys which exhibit obvious precipitation strengthening potential.
\end{abstract}

Keywords: multimodal; AZ91 alloy; equal channel angular pressing; aging

\section{Introduction}

As the lightest structural metal on earth, magnesium has obvious advantages of rich resource, ease of recycling, and good biocompatibility [1-3]. These unique properties make magnesium and its alloys attractive for automotive, aerospace, and biomedical applications. Among various magnesium alloys, Mg-9Al-Zn alloys (AZ91) have become the most common and cost-effective commercial Mg alloys due to their relatively high strength, good machinability, excellent corrosion resistance, and good damping capacity. However, the formability and ductility of AZ91 alloys is usually poor because of their hexagonal close packed lattice and the abundant dendritic second phases, which severely restrict its widespread industry applications [4].

To improve the mechanical properties of AZ91 alloys, extensive research has already been carried out to develop fine/ultrafine grained AZ91 alloys by means of severe plastic deformation (SPD) [4-10]. Among several SPD methods, equal channel angular pressing (ECAP) is the most important and widespread since Segal's pioneering work [11]. ECAP can be effective on refining the microstructure of magnesium alloys by imposing high total strains via simply increased ECAP passes, and it could also produce large bulk samples without changing their shapes [12-14]. More details on the ECAP can be found in two comprehensive reviews [15,16]. For example, Mathis et al. reported that an ultrafine grained (UFG) AZ91 alloy prepared by ECAP exhibited improved tensile strength of $370 \mathrm{MPa}$, but its 
ductility was diminished to 5.5\% [17]. Moreover, Chen et al. conducted a two-step ECAP on the hot-rolled AZ91 alloy and prepared a UFG alloy with average grain size of $2 \mu \mathrm{m}$ [4]. The ultimate tensile strength of this UFG AZ91 alloy was increased remarkably to $417 \mathrm{MPa}$, with a moderate elongation of $8.45 \%$. The grain refinement and precipitation of the $\mathrm{Mg}_{17} \mathrm{Al}_{12}$ phase during ECAP were accountable for the high strength. Although the homogeneous structure of fine/ultrafine grains obtained via ECAP could efficiently improve the mechanical properties of AZ91 alloys, a trade-off between strength and ductility still exists. Thus, it is still quite challenging to prepare a magnesium alloy with simultaneous high strength and good ductility. Moreover, in order to achieve a homogeneous grain structure, high-pass ECAP is usually needed, which unfavorably complicates the manufacturing process.

Some recent studies have showed that developing a bimodal grain structure is a feasible strategy for preparing metals with synchronous high strength and high ductility [18]. Wang et al. reported that an AZ91 alloy sheet with a bimodal structure processed by hard-plate rolling (HPR) simultaneously achieved high strength (tensile strength of $371 \mathrm{MPa}$ ) and high ductility (elongation of 23\%) [19]. The superior properties should be mainly attributed to the cooperation effect of the bimodal grain structure and weakened texture, where the former facilitates a strong work hardening while the latter promotes the basal slip. Unfortunately, to our knowledge, reports on bimodal magnesium alloys prepared by other processing methods were rather scarce.

The objective of this work was to develop a multimodal grain structured AZ91 alloy through a combined processing route of low-pass ECAP, and thus to simultaneously improve the strength and ductility of this alloy. The main focus of this work was on an in-depth analysis of the microstructure evolution (electron back-scattered diffraction (EBSD), scanning electron microscope/energy dispersive spectrometer (SEM/EDS), transmission electron microscope (TEM), and X-ray diffraction (XRD)) and its resultant excellent mechanical properties. This work could provide a theoretical guidance for the strengthening-toughening design of novel magnesium alloys.

\section{Materials and Methods}

In this work, a commercial as-cast AZ91 alloy (chemical compositions of 9 wt. $\% \mathrm{Al}, 1 \mathrm{wt} . \% \mathrm{Zn}$, and $0.5 \mathrm{wt} . \% \mathrm{Mn}$ ) was used. The combined processing route was composed of three major steps. First, the cubic samples with a dimension of $20 \mathrm{~mm} \times 20 \mathrm{~mm} \times 45 \mathrm{~mm}$ were solid solution treated at $693 \mathrm{~K}$ for $25 \mathrm{~h}$ and then immediately quenched in water. Thereafter, a home-made rotary-die ECAP (RD-ECAP) was employed on these samples at $573 \mathrm{~K}$ for 6 passes, followed by quickly cooling in water. The operation principle of RD-ECAP can be found in the supplementary material and our earlier work $[20,21]$. Prior to RD-ECAP, the sample and die were held at $573 \mathrm{~K}$ for $15 \mathrm{~min}$ together. Finally, a portion of the ECAP samples was aged at $523 \mathrm{~K}$ for $5 \mathrm{~h}$.

The microstructures of various AZ91 samples were characterized by the optical microscope (OM), scanning electron microscope (SEM, Hitachi, Tokyo, Japan, S4800), transmission electron microscope (TEM, JEM 2100), and X-ray diffraction (XRD, Bruker, Karlsruhe, Germany, D8 advance). Prior to the observation, the OM and SEM samples were mechanically polished and etched with an acetic picric solution ( $5 \mathrm{~mL}$ acetic acid, $6 \mathrm{~g}$ picric acid, $10 \mathrm{~mL}$ water, and $100 \mathrm{~mL}$ ethanol), and the TEM samples were prepared using jet polishing. Moreover, the microstructure evolution was assessed through electron back-scattered diffraction (EBSD) on a Hitachi S-3400N SEM (Hitachi, Tokyo, Japan) equipped with an HKL-EBSD system. Step size for mapping was $100 \mathrm{~nm}$ to achieve sufficient 161 resolution to reveal the microstructure. The EBSD samples were grinded and polished, and then ion polished. The tensile tests were conducted using a CMT5105 electronic universal testing machine (MTS, Shenzhen, China) at room temperature and strain rate of $5 \times 10^{-4} \mathrm{~s}^{-1}$. Dog-bone shaped tensile specimens (gauge size of $6 \mathrm{~mm} \times 2 \mathrm{~mm} \times 3 \mathrm{~mm}$ ) were machined from the processed billets with the loading axis parallel to the extruded direction. 


\section{Results}

\subsection{Microstructure Evolution}

\subsubsection{The Initial States}

Figure 1a,b shows the optical microstructure of the as-received AZ91 cast alloy. Its microstructure was characterized by the typical dendritic structure with coarse grains, as shown in Figure 1 a. This dendritic structure consisted of $\alpha-\mathrm{Mg}$ matrix, $\mathrm{Mg}_{17} \mathrm{Al}_{12}-\gamma$ phase precipitates, and $\alpha+\gamma$ eutectic phases (Figure 1b). The coarse eutectic phases were distributed along the grain boundaries, which were the products of a divorced eutectic reaction from the Al enriched part of the liquid metal. A majority of the $\gamma$-phases were aligned around the eutectic phases, but a few $\gamma$-phases were dispersed inside $\alpha$-Mg grains. The XRD pattern shown in Figure 1 c confirmed the existence of $\mathrm{Mg}_{17} \mathrm{Al}_{12}$ and $\alpha-\mathrm{Mg}$ phases. The average grain size of this cast alloy was $200 \mu \mathrm{m}$, measured through the intercept method.
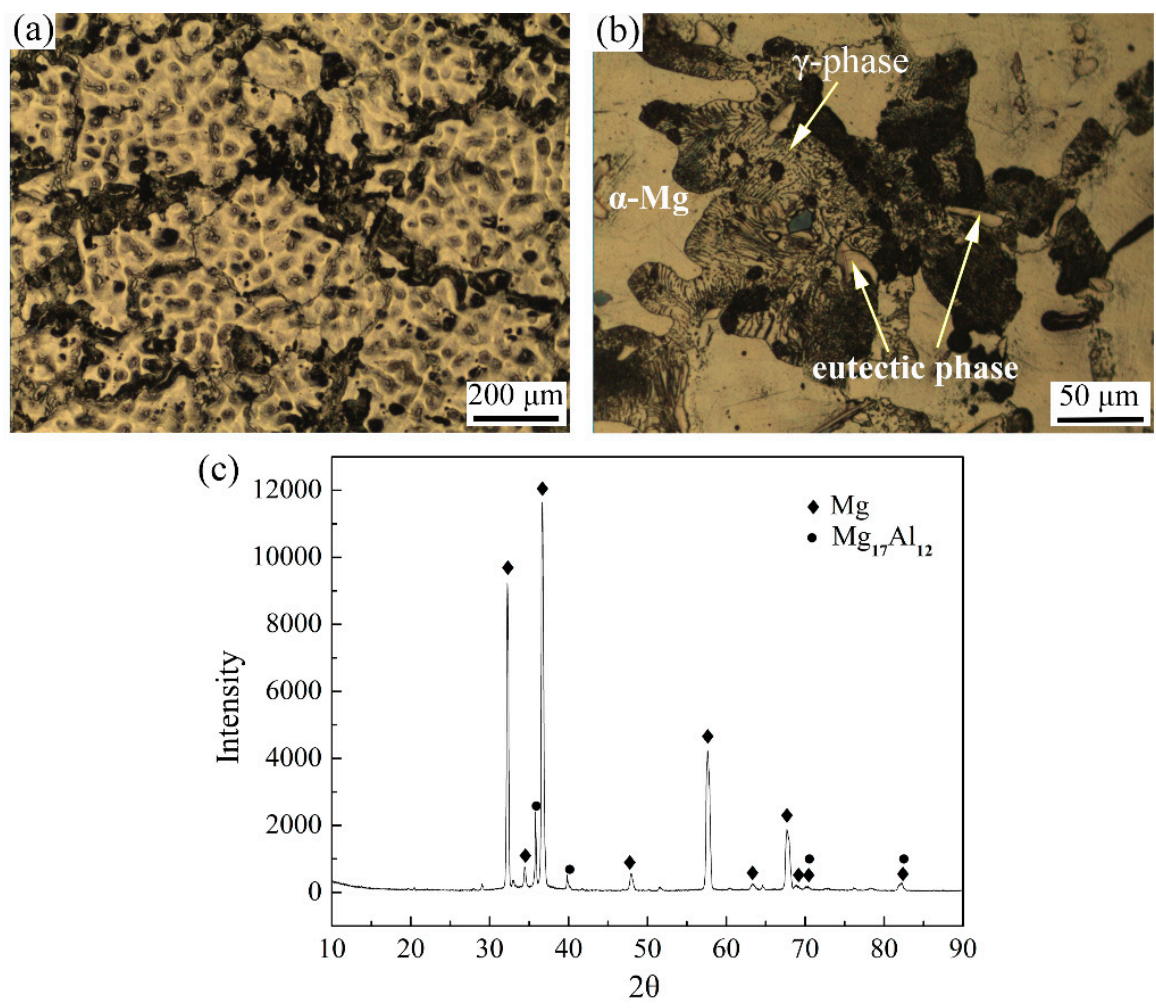

Figure 1. Optical micrographs of as-cast Mg-9Al-Zn (AZ91) alloy at (a) low and (b) high magnifications. (c) The corresponding X-ray diffraction (XRD) pattern.

\subsubsection{Microstructure Evolution during Processing}

After solid solution treatment at $693 \mathrm{~K}$ for $25 \mathrm{~h}$, most of the $\gamma$-precipitates and eutectic $\gamma$-phases were dissolved into the matrix, as shown in Figure 2a. However, there was still a small amount of $\gamma$-precipitates remaining, which were confirmed by the SEM and EDS results of Figure 2b,c. 

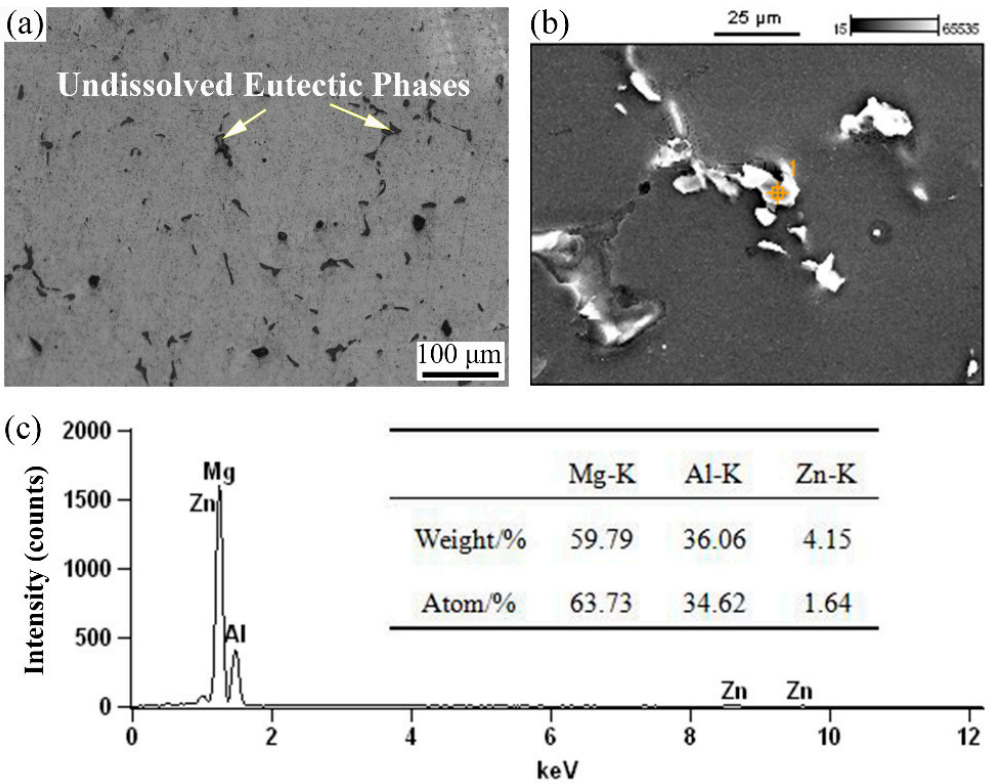

Figure 2. Microstructure of the solution heat-treated AZ91 alloy: (a) Optical micrograph; (b) scanning electron microscope (SEM) micrograph; (c) energy dispersive spectrometer (EDS) analysis of the undissolved phase.

After $6 \mathrm{p}-\mathrm{ECAP}$, the grain size of the $\alpha-\mathrm{Mg}$ was remarkably refined, but some coarse grains were still obvious, as shown in Figure 3a. Interestingly, heterogeneous precipitates were observed, which mainly comprised three regions, the uniform precipitates regions in fine grains, the precipitatefree regions, and the high-density precipitates regions in coarse grains. After short-time aging, the multimodal grain structure and heterogeneous precipitates were still maintained. However, the precipitate-free regions disappeared, and the density of the precipitates in the uniform precipitate regions increased slightly (Figure 3b). To further understand the microstructure evolutions, EBSD, SEM, and TEM observations were performed on both ECAP and aged alloys.
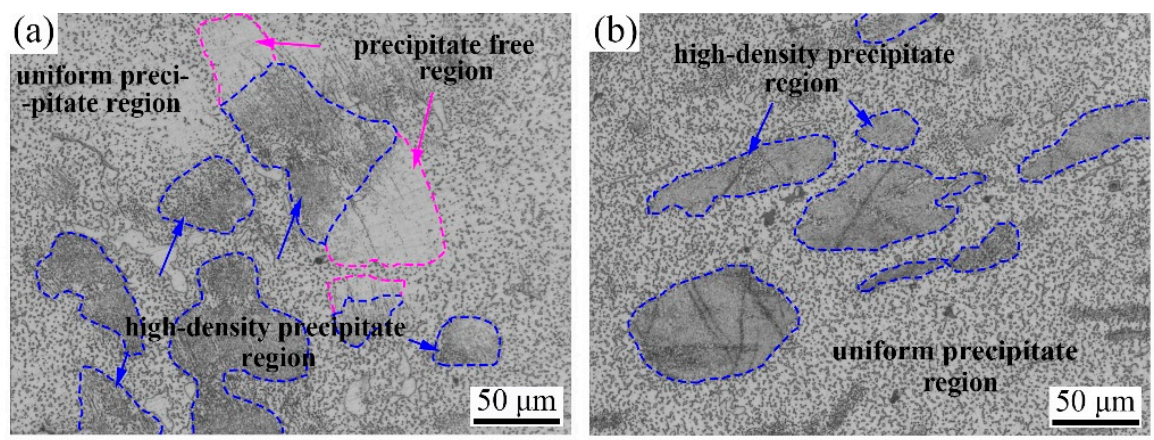

Figure 3. Optical micrographs of the AZ91 alloy processed by (a) equal channel angular pressing (ECAP) and (b) ECAP-aging.

Figure 4 shows the EBSD inverse pole figure (IPF) maps and grain size statistic of the ECAP and ECAP-aged AZ91 alloys along the extruding direction. It was noteworthy that the ECAP alloy possessed a mixed grain structure composed of coarse grains and fine grains, representing a typical multimodal grain structure, as shown in Figure $4 \mathrm{a}$. The fine grains $(<20 \mu \mathrm{m})$ reached their peak at about $4 \mu \mathrm{m}$ and had an average size of $5.82 \mu \mathrm{m}$. Meanwhile, the coarse grains exhibited an average grain size of $135.55 \mu \mathrm{m}$, and the volume fraction was about $63 \%$. After short-time aging, the grain structure remained a multimodal distribution, but with a slight increase in the fine grains $(5.96 \mu \mathrm{m})$ facilitated by thermal activation (Figure $4 \mathrm{c}$ ). However, both the volume fraction (38.5\%) and the 
average grain size $(73.61 \mu \mathrm{m})$ of coarse grains decreased, indicating the refinement of the coarse grains occurred during aging. This was ascribed to the static recrystallization during aging, which will be discussed later.

The mechanisms of the formation of the multimodal structure were further dissected. Figure 5 shows the distribution of the recrystallized, substructure, and deformed grains for the ECAP and ECAP-aged alloys. It was obvious that partial dynamic recrystallization occurred during ECAP (Figure 5a). In other words, the coarse deformed grains were replaced by a set of the new fine equiaxed grains gradually during ECAP. In fact, the coarse substructure grains in the ECAP alloy still possessed an area fraction of $65.94 \%$, as shown in Figure $5 \mathrm{c}$. Thus, a multimodal grain structure with fine recrystallized grains and coarse deformed grains was generated after $6 \mathrm{p}$-ECAP. Moreover, after aging at $523 \mathrm{~K}$ for $5 \mathrm{~h}$, the area fraction of the recrystallized grains increased from $27.59 \%$ to $64.03 \%$, which was accompanied by the decrease in both the fraction and size of the substructure grains, as shown in Figure $5 b, c$. This indicated that an incompletely static recrystallization occurred during aging, which transformed the substructure grains to the new fine equiaxed grains. Due to the relatively short aging time, static recrystallization did not take place completely, and a certain amount of the coarse grains were retained. Therefore, the present low-pass ECAP and short time aging promoted the occurrence of incompletely thermodynamic recrystallization and finally caused the formation of the multimodal grain structure.
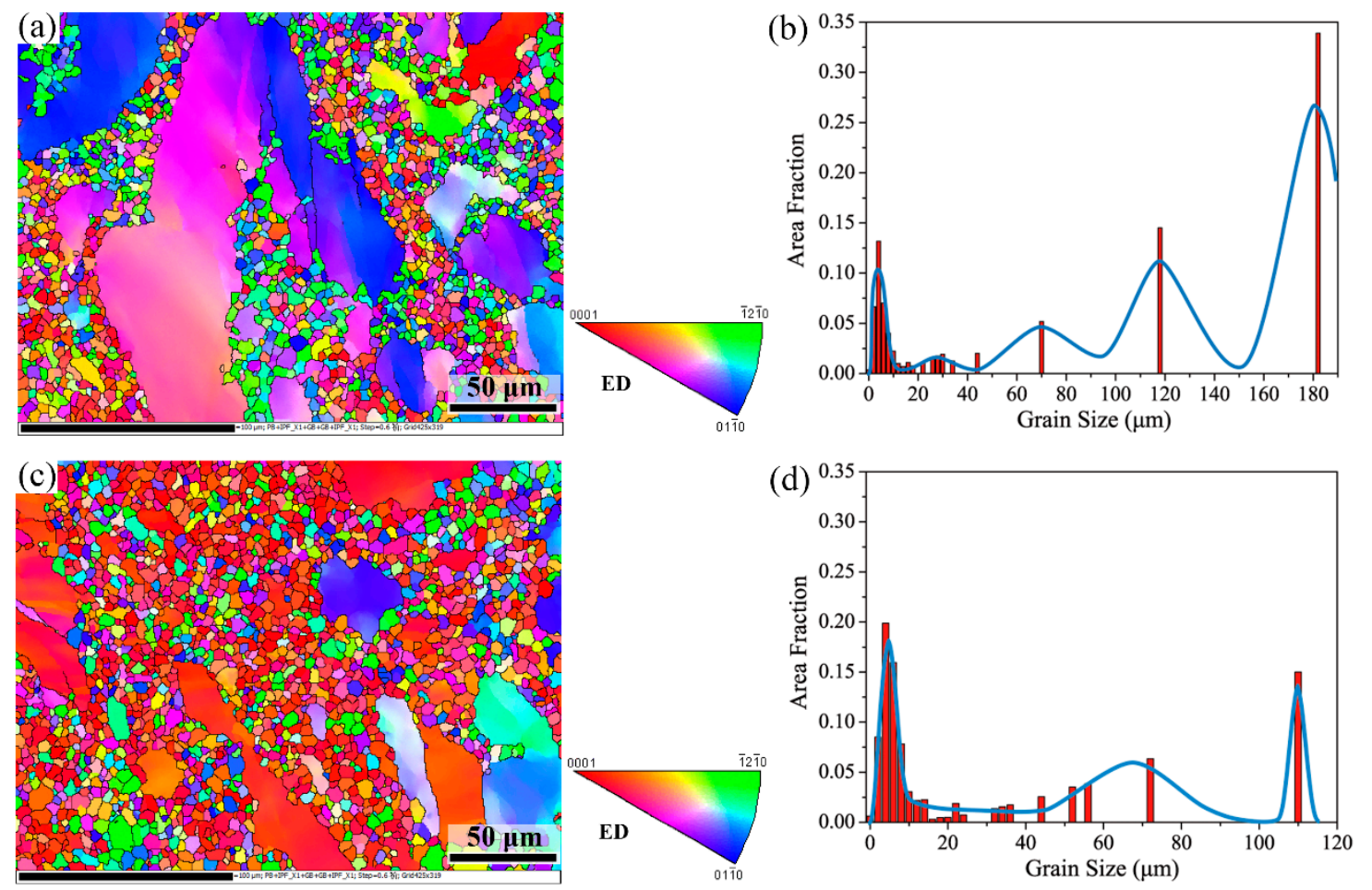

Figure 4. Inverse pole figure (IPF) maps and grain size statistics of the AZ91 alloy processed by $(\mathbf{a}, \mathbf{b})$ ECAP and (c,d) ECAP-aging. 

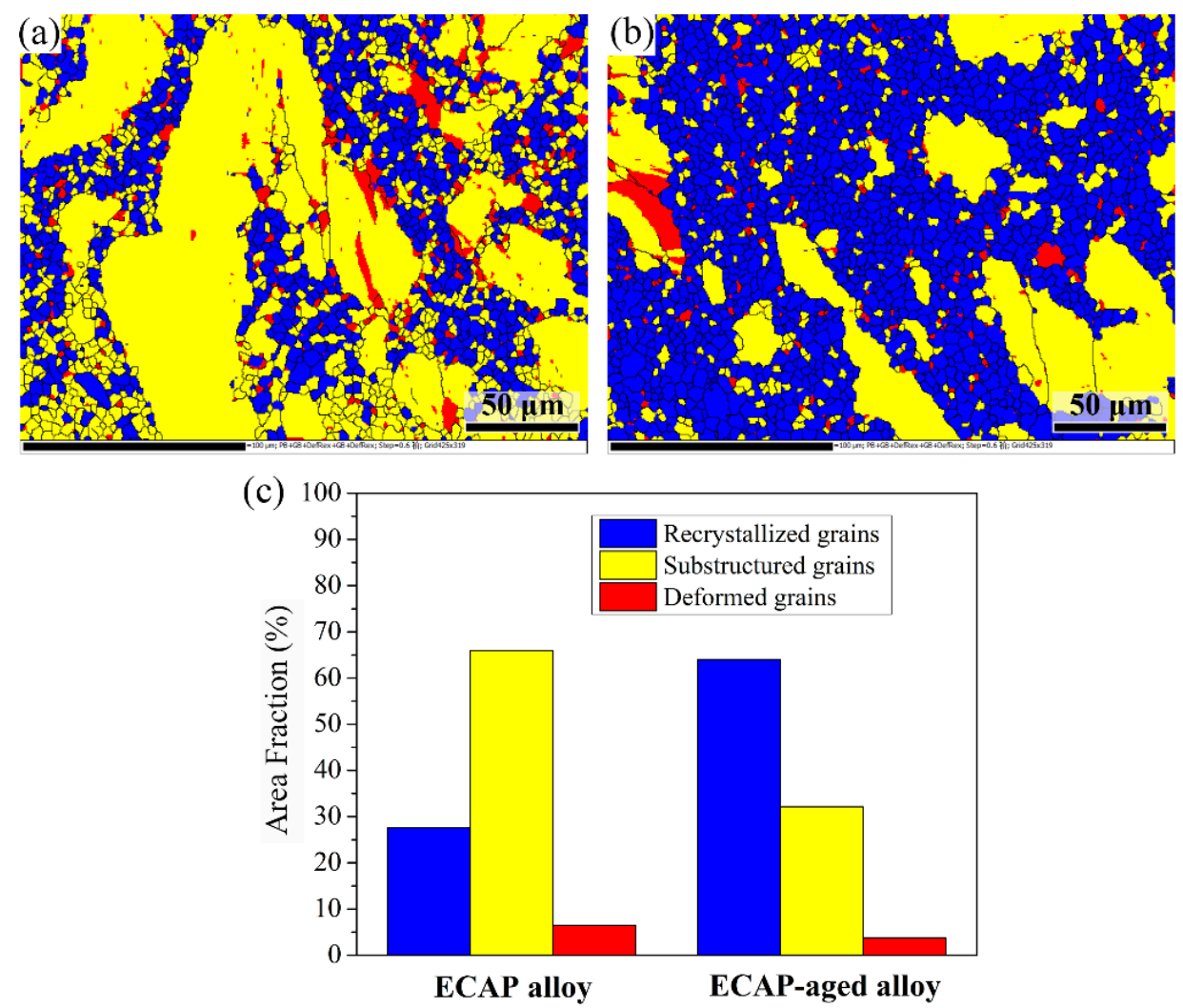

Figure 5. Electron back-scattered diffraction (EBSD) recrystallization fraction maps of the AZ91 alloy processed by (a) ECAP; (b) ECAP-aging. (c) Area fraction of recrystallized, substructure, and deformed grains.

Figure $6 a, b$ shows the Kernel Average Misorientation (KAM) maps of the ECAP and ECAP-aged AZ91 alloys. KAM is usually used to represent average misorientation less than $5^{\circ}$ between a given point and its nearest neighbors which belong to the same grain. Therefore, the KAM map can be used to assess local plastic strain and thus reflect, to some extent, the density of dislocations. It can be seen that the coarse grains, especially their nearby boundaries, possessed high KAM value both in the ECAP and ECAP-aged AZ91 alloys, indicating a high dislocation density in these regions. This provided further evidence that the coarse grains were the deformed or substructure grains. Previous research reported that the partial dynamic recrystallization of $\mathrm{Mg}$ and its alloys during thermal-mechanical deformation was conducted along the pre-existing coarse grain boundaries [22]. Hence, the coarse grains in the AZ91 ECAP alloy were the inner core areas of the large initial grains. Figure $6 \mathrm{c}$ shows the KAM value versus relative frequency. It is apparent that the relative frequency of low KAM values (less than $0.5^{\circ}$ ) was higher in the ECAP-aged alloy, while high KAM values were more pronounced in the ECAP alloy, suggesting that dislocation density in the ECAP-aged alloy was lower than that in the ECAP alloy. This demonstrated that the new fine grains nucleated along pre-existing coarse grain boundaries owing to their high dislocation density during aging, that is, occurrence of static recrystallization. Above all, the present result demonstrated that incomplete recrystallization along the pre-existing coarse grain boundaries was the fundamental reason for the formation of the multimodal grain structure. 

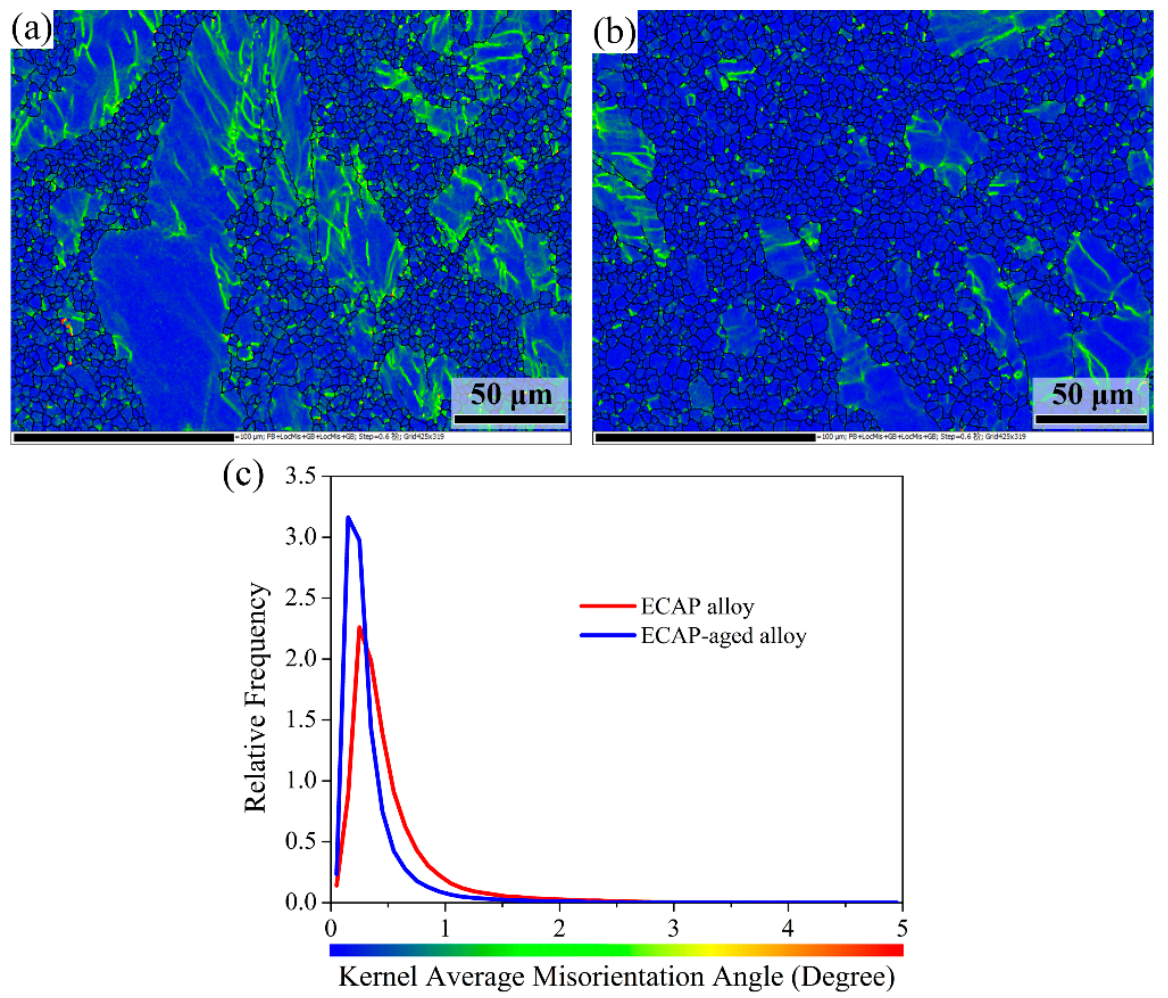

Figure 6. Kernel Average Misorientation (KAM) maps of the AZ91 alloy processed by (a) ECAP and (b) ECAP-aging. (c) KAM versus relative frequency.

Figure 7 shows the SEM images of the AZ91 ECAP alloy. Consistent with the OM images, the SEM images showed that the second phase particles were not uniformly distributed. Some coarse grains possessed high-density precipitates (Figure 7a), while other coarse grains were almost precipitate-free (Figure $7 \mathrm{~b}$ ). The high-magnification SEM image of the fine grain regions (Figure 7c) highlighted the uniformly distributed cobblestone-like fine precipitates with an average size of $0.5 \sim 3 \mu \mathrm{m}$, representing a typically continuous precipitation morphology. These particles were dynamically generated during ECAP. Notably, these precipitates were dispersed along grain boundaries, but almost no precipitates were observed inside the fine grains. This observation suggested that these fine grains were partial dynamic recrystallized grains, which were activated by the fine precipitates through a particle-stimulated nucleation (PSN) mechanism [23,24]. These precipitates along grain boundaries can stabilize the microstructure and suppress grain growing, giving rise to the slightly increased fine grains after subsequent aging of the ECAP alloy. Moreover, the precipitates in the high-density precipitate regions in the coarse grains had a small average size of $0.74 \mu \mathrm{m}$, as illustrated in Figure $7 \mathrm{~d}$.

Figure 8 provides the SEM observations of the AZ91 ECAP-aged alloy. In stark contrast to the ECAP alloy, the ECAP-aged alloy was devoid of the precipitate-free regions (Figure 8a), indicating that the fine $\gamma$-phase preferentially formed in these coarse grains during aging. This can be ascribed to the high dislocation density of the coarse grains, as shown in Figure 6a. Moreover, the density of the precipitates both in high-density precipitate regions and uniform precipitate regions was slightly increased, while no obvious growth of the precipitates was found, as shown in Figure 8b,c. Therefore, precipitation mainly took place in the precipitate-free region, with continuous precipitation morphology during aging.

Above, SEM observations showed two different kinds of precipitation regions in both ECAP and ECAP-aged alloys: High-density precipitate colonies and low-density precipitate colonies. The low-density precipitate colonies occupied most parts of the microstructures, interspersed by some high-density precipitate colonies. The precipitates in the high-density precipitate colonies were much smaller than those in low-density precipitate colonies. The high-density precipitate colony 
corresponded to the coarse grains (Figures 7 and 8). Therefore, it can be concluded that the high-density dislocations in the coarse grains promoted the high-density precipitates in their interior.
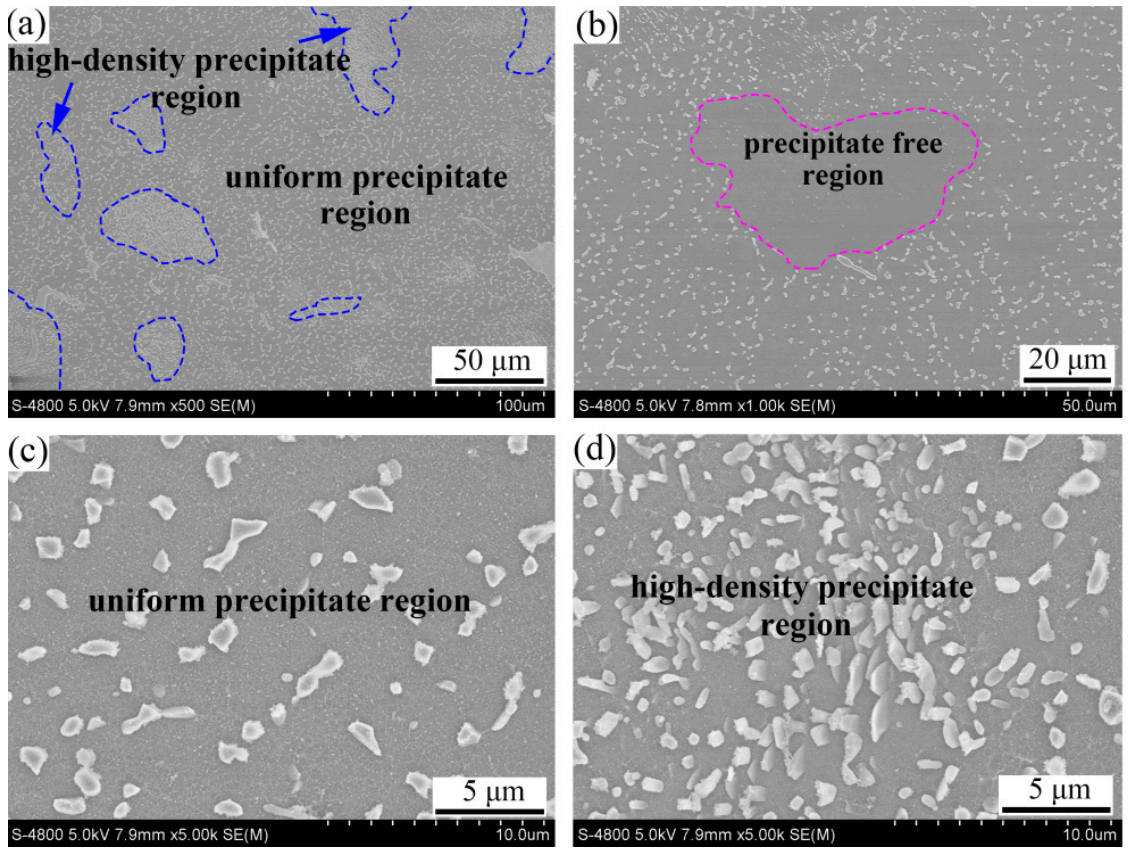

Figure 7. SEM micrographs of the AZ91 ECAP alloy. (a) the low-magnification SEM image showing high-density precipitate region and uniform precipitate region; (b) the SEM image showing precipitate free region; (c, d) the details of the marked regions in (a).
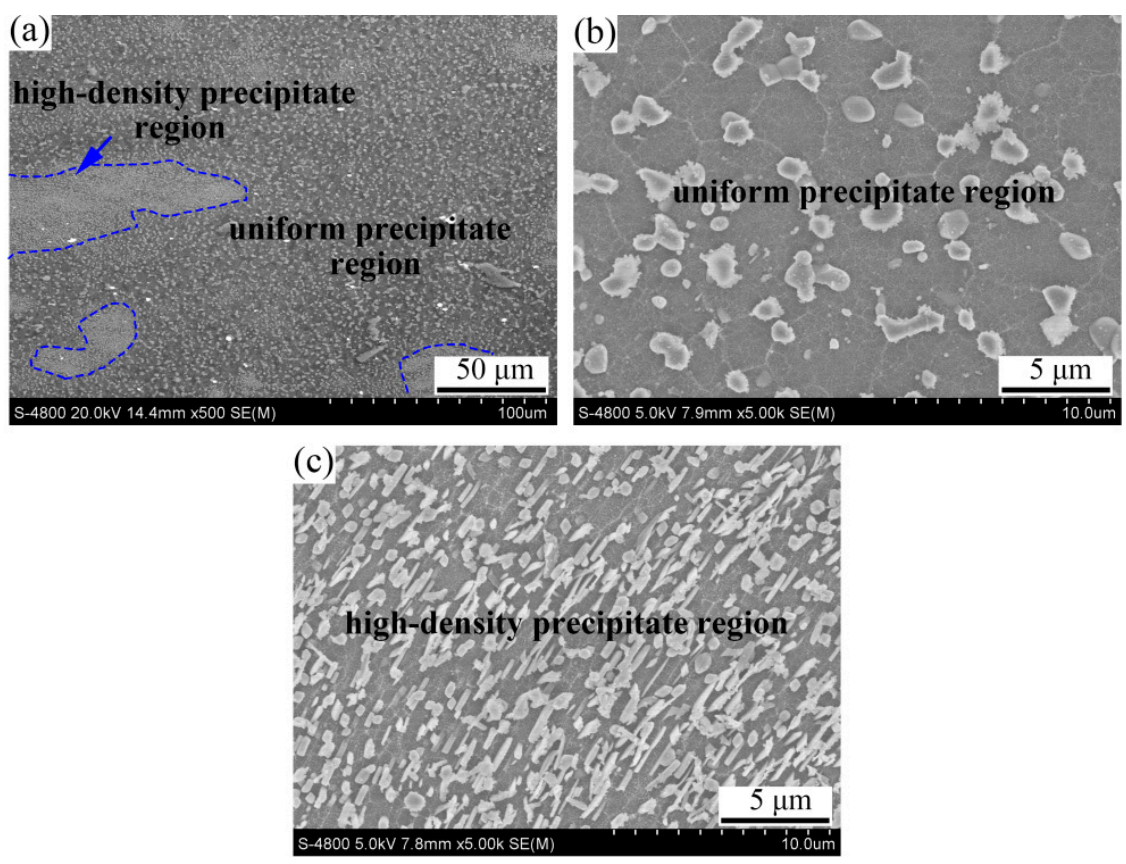

Figure 8. SEM micrographs of the AZ91 ECAP-aged alloy. (a) the low-magnification SEM image showing high-density precipitate region and uniform precipitate region; $(\mathbf{b}, \mathbf{c})$ the details of the marked regions in (a).

The TEM micrographs of the ECAP and ECAP-aged alloy are shown in Figure 9. It can be seen that the dispersed precipitates in the fine grain regions of the ECAP alloy were mainly located in the grain boundaries, while a few fine precipitates were found in the grain interior (Figure 9a). Figure 9b shows 
the precipitation morphology of the high-density precipitate regions of the ECAP alloy. These fine precipitates dispersed in a coarse grain, which further verified that the high-density precipitate regions mainly existed in the coarse grains. After aging, the density of the precipitates in the fine grain regions increased, as shown in Figure 9c. Figure 9d shows the enlargement of the precipitates within a coarse grain of the ECAP-aged alloy. Some spherical nanoscale precipitates (marked by yellow arrows) occurred in the coarse grain interior with a very low density. Therefore, these nanoscale precipitates slightly contributed to strengthening of alloy.
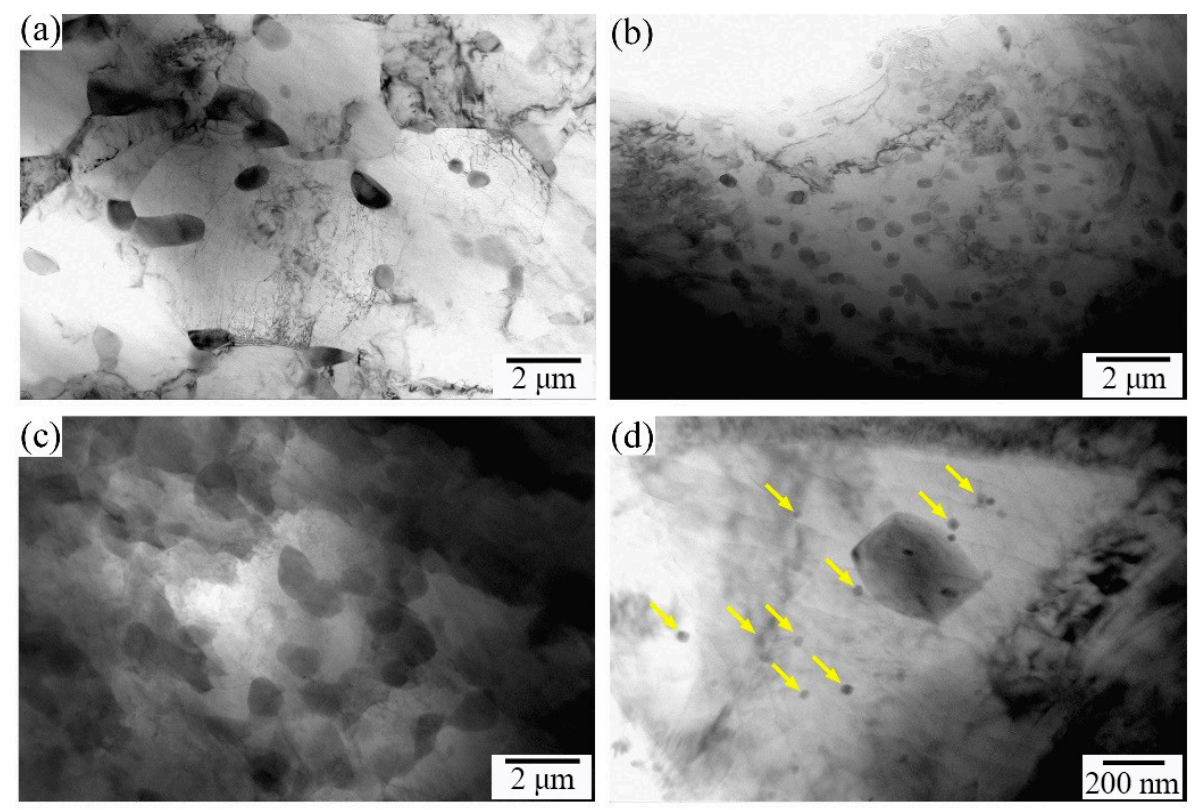

Figure 9. Transmission electron microscope (TEM) images of the AZ91 alloy. (a) The fine grain regions and (b) the high-density precipitate regions of the ECAP alloy. (c) The fine grain regions and (d) the enlargement of the precipitates within a coarse grain of the ECAP-aged alloy.

\subsection{Mechanical Properties}

Figure 10a shows the stress-strain curves of the as-cast, ECAP, and ECAP-aged AZ91 alloy. The yield strength (YS), ultimate tensile strength (UTS), and elongation to failure are also illustrated in Figure 10b. It was apparent that the as-cast alloy possessed the lowest YS (70 MPa), UTS (95 MPa), and poor ductility (elongation of 2.8\%). After 6p-ECAP, the AZ91 alloy showed a more than threefold increase in YS (252 MPa) and UTS (282 MPa), and fivefold increase in elongation (14\%) compared to the as-cast alloy. Interestingly, the ECAP-aged alloy possessed an optimal strength (YS of $270 \mathrm{MPa}$ and UTS of $360 \mathrm{MPa}$ ) and remarkably improved ductility (elongation of $21.2 \%$ ), which were the best strength-ductility combination. This result indicated that the combined processing route of low-pass ECAP with short-time aging can simultaneously improve both the strength and ductility of the AZ91 alloy.

Figure 10c compares the UTS and elongation of the AZ91 ECAP-aged alloys with AZ91 processed by other processing approaches adopted by other studies, including ECAP [8,17,25-32], accumulative roll bonding [9], differential speed rolling [33,34], rolling [35,36], and multidirectional forging [5]. It is obvious that there was a trade-off between the strength and ductility of the AZ91 alloy processed by conventional deformation or SPD. However, the mechanical properties of the current AZ91 ECAP-aged alloy clearly fell outside of the reported ordinary strength-ductility trade-off. Moreover, the superior strength of the current AZ91 ECAP-aged alloy was almost better than that of all RE-free Mg alloys and was even comparable to that of some Mg-RE alloys (Figure 10d). Compared to our previous work [32], the compact process route (low ECAP pressing passes and short aging time) manifested an AZ91 alloy in both high strength and good ductility. Meanwhile, compared to high strength Mg-RE alloys, this cost-effective AZ91 alloy possessed much higher ductility, and low density and cost. 

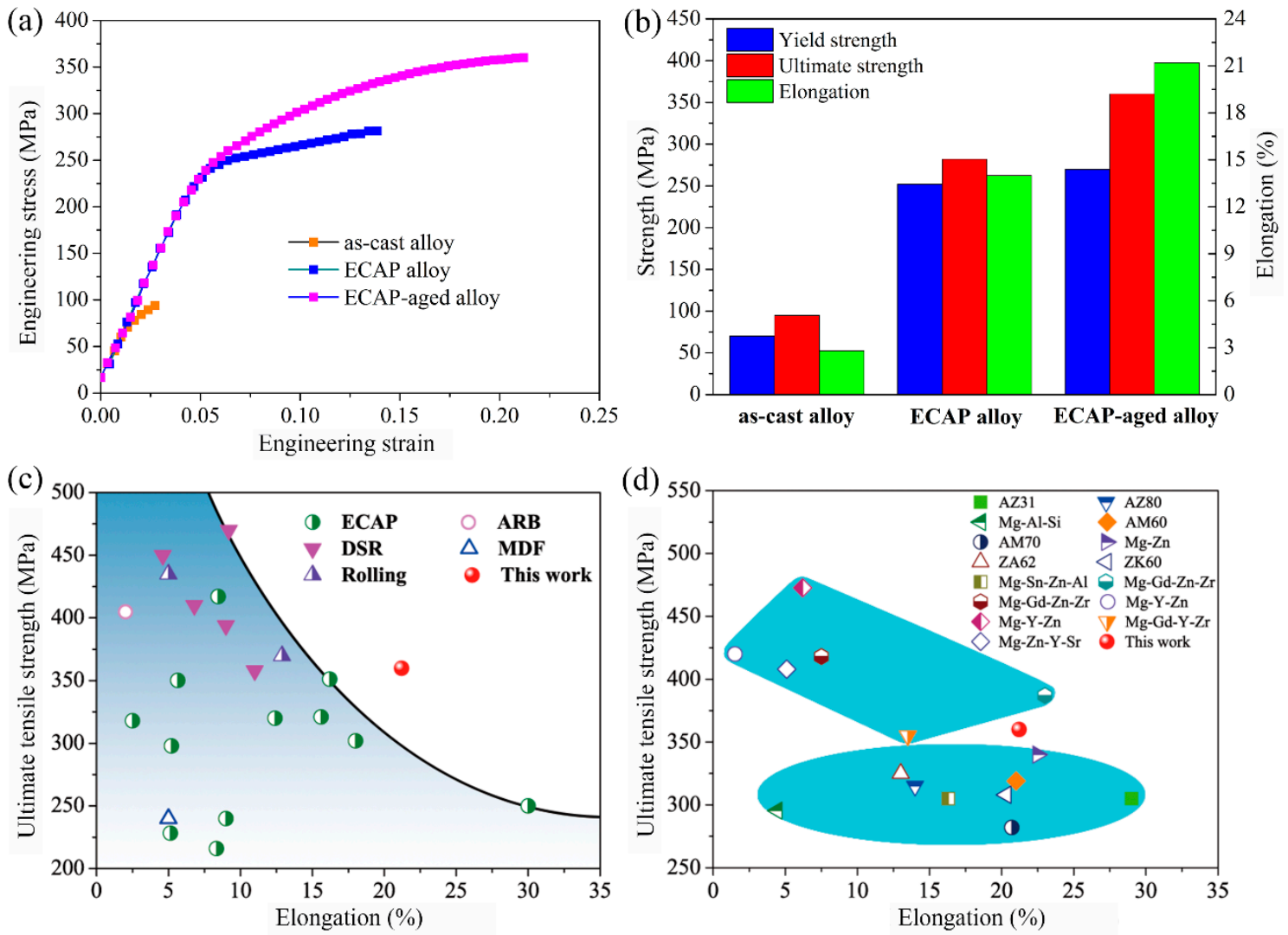

Figure 10. (a) Typical stress-strain curves of the AZ91 alloy; (b) The summary of yield strength, ultimate strength, and elongation to failure; (c) The ultimate tensile strength versus total tensile elongation of the AZ91 alloys in comparison with available literature data; (d) The ultimate tensile strength versus elongation of Mg-RE alloys and RE-free Mg alloys prepared by ECAP [37-51].

\section{Discussion}

The present work provided an alternative processing method (a combined use of low-pass ECAP with short-time aging) to simultaneously improve the strength and ductility of AZ91 alloys. The developed method held the advantages of a short process, high efficiency, and low cost. By employment of this method, we obtained a multimodal grain microstructured AZ91 alloy with both high strength and good ductility.

It is of great interest to discuss the underlying mechanisms behind the simultaneously improved strength and ductility of the AZ91 alloy. The EBSD observation clearly revealed that the grain refinement strengthening (i.e., the formation of fine grains) mainly contributed to the increased strength. In fact, the volume fraction of fine grains $(<20 \mu \mathrm{m})$ reached $37 \%$ in the ECAP alloy, which further increased to $61.5 \%$ after aging (Figure 4 ). A large number of fine grains mean a large number of high angle grain boundaries (HAGBs), which are widely believed to provide better strengthening during deformation because they are more effective in blocking dislocations [52,53]. Hence, the ECAP-aged alloy exhibited higher strength than the ECAP alloy. This conclusion was further corroborated by the distribution of grain boundary misorientation, as shown in Figure 11. The fraction of HAGBs $\left(\theta>15^{\circ}\right)$ for the ECAP-aged alloy ( 79.2\%) was much higher than that for the ECAP alloy ( 59\%). Additionally, the average misorientation angle of the ECAP-aged alloy also apparently increased from $28.77^{\circ}$ to $41.32^{\circ}$ after aging. In addition, the substructure and high dislocation density in the coarse grains (Figures 5 and 6) could hinder the dislocation motion and thus contributed to the increased strength. This effect was more prominent in the ECAP alloy because of its coarser grains. 

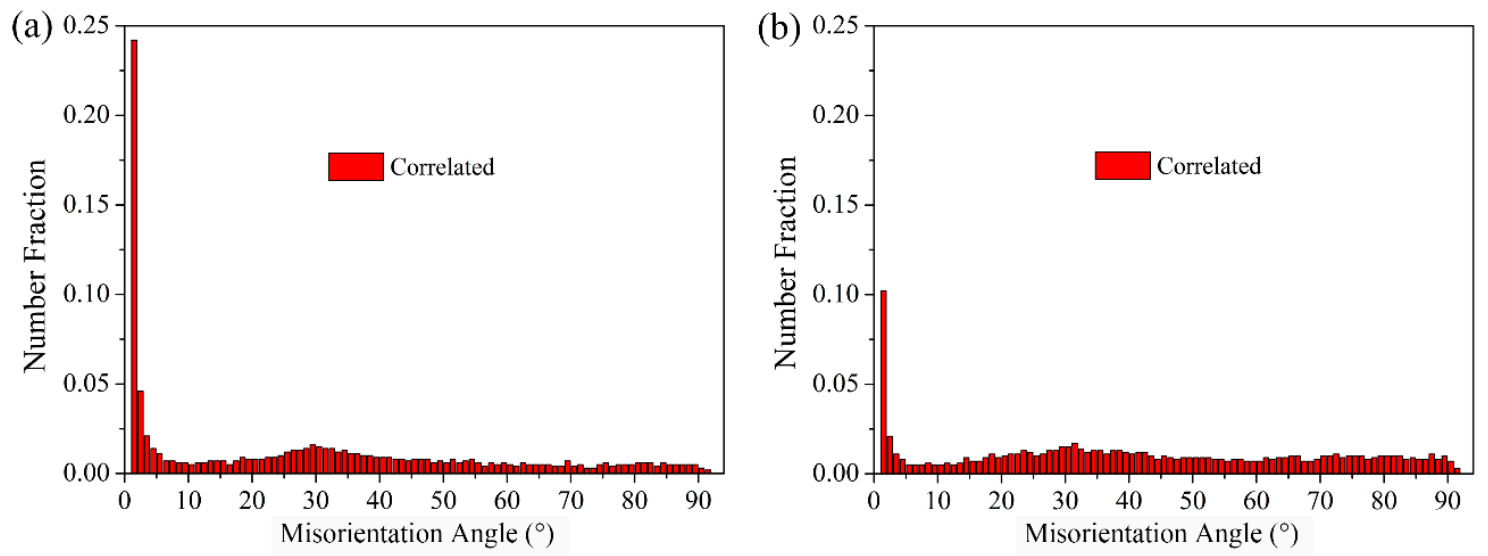

Figure 11. Misorientation distributions of the AZ91 alloy processed by (a) ECAP and (b) ECAP-aging.

Moreover, it was proposed that the multimodal grain structure gave rise to the so-called back-stress strengthening [54]. During deformation, dislocations would pile up in the coarse grains and hence generate geometrically necessary dislocations near the fine/coarse grain interfaces, resulting in the formation of a long-range back-stress. The back-stress made it difficult for dislocations to slip in the coarse grains until the surrounding fine grains started to yield at a larger global strain. In other words, the back-stress increased the flow stress of the soft coarse grains by the time the whole sample was yielding.

The fine and high-density precipitates could also contribute to the improvement of strength via the Orowan mechanism. In fact, the low strength and poor ductility of the AZ91 cast alloy, to a great extent, was related to the abundant and coarse dendritic second phases. Here, a mass of the fine $\gamma$-phase particles precipitated from the supersaturated $\mathrm{Mg}$ matrix, due to the thermo-mechanical effect during ECAP processing. The fine and high-density precipitates dispersed in the matrix can obstruct the dislocation motion and cause a pinning effect on the grain boundaries during tensile deformation, which significantly enhanced the strength.

In addition, it was necessary to discuss the underlying mechanisms behind the high ductility of the present AZ91 alloy. Grain refinement was one of the main contributors. With the increase of grain boundaries, stress could be dispersed to a larger area. Thus, the stress concentration was reduced. In addition, the fine grains would contribute to the activation of slip systems, that is, basal slip and non-basal slip. The multimodal grain structure was also responsible for the improvement of ductility. According to the study of Zhu et al., strain partitioning would exist during the deformation of heterogeneous materials, and the occurrence of strain gradients led to back-stress work hardening [49]. Wang et al. also attributed the high uniform ductility of the HPRed AZ91 alloy to the strong work hardening resulting from the multimodal grain structure [19]. The back-stress work hardening was beneficial to preventing necking during tensile testing, thus improving ductility. Therefore, it was reasonable to believe that the increased ductility should be mainly attributed to the grain refinement and the formation of a multimodal grain structure.

\section{Conclusions}

In the present work, we presented a multimodal grain structured AZ91 alloy with both high strength and good ductility, prepared through a combined processing route of low-pass ECAP with short-time aging. The preparation method held the advantages of a short process, high efficiency, and low cost. The main conclusions were drawn as follows:

(1) A multimodal grain structure consisting of coarse grains and fine grains was achieved in the AZ91 alloy after 6p-ECAP. After further short-time aging, the volume fraction of the fine grains increased due to the occurrence of static recrystallization, accompanied by a slight increase in the fine grains size. 
(2) A heterogeneous precipitation was observed in the ECAP alloy, which consisted of low-density precipitate colonies interspersed by some high-density precipitate colonies and precipitate-free colonies. After short-time aging, the heterogeneous precipitates were maintained, but the precipitate-free colonies disappeared, and the density of the precipices increased slightly.

(3) Simultaneous high strength and good ductility (360 MPa and 21.2\%, respectively) were obtained in the bulk AZ91 ECAP-aged alloy. The high strength was attributed to the synergistic effect of grain refinement, back-stress strengthening, and precipitation strengthening. The favorable ductility was ascribed to the grain refinement and multimodal grain structure.

Author Contributions: A.M., J.S. and J.J. designed the project and guided the research; Z.Y., J.S. and H.L. prepared the manuscript; Z.Y., D.S., C.W. and Y.Y. performed the experiment and analyzed the data; D.S. and C.W. prepared the figures; A.M., Y.Y. and J.J. reviewed the manuscript.

Funding: This work was supported by the National Natural Science Foundation of China (Grant No. 51774109), the Fundamental Research Funds for the Central Universities (Grant No. 2018B48414), the Natural Science Foundation of Jiangsu Province (Grant No. BK20160867 and BK20160869), the Key Research and Development Project of Jiangsu Province of China (Grant No. BE2017148), and the National Natural Science Foundation of China (Grant No. 51701065).

Conflicts of Interest: The authors declare no conflict of interest.

\section{References}

1. Liu, Y.; Kang, Z.X.; Zhang, J.Y.; Wang, F.; Li, Y.Y. Influence of pre-solution treatment on microstructure and mechanical properties of Mg-Gd-Nd-Zn-Zr Alloy processed by ECAP. Adv. Eng. Mater. 2016, 18, 833-838. [CrossRef]

2. Wu, G.S.; Lbrahim, J.M.; Chu, P.K. Surface design of biodegradable magnesium alloys-A review. Surf. Coat. Technol. 2013, 233, 2-12. [CrossRef]

3. Zong, X.M.; Zhang, J.S.; Liu, W.; Zhang, Y.T.; You, Z.Y.; Xu, C.X. Corrosion behaviors of Long-Period stacking ordered structure in mg alloys used in biomaterials: A review. Adv. Eng. Mater. 2018, 20. [CrossRef]

4. Chen, B.; Lin, D.L.; Jin, L.; Zeng, X.Q.; Lu, C. Equal-channel angular pressing of magnesium alloy AZ91 and its effects on microstructure and mechanical properties. Mater. Sci. Eng. A 2008, 483, 113-116. [CrossRef]

5. Nie, K.B.; Deng, K.K.; Wang, X.J.; Xu, F.J.; Wu, K.; Zheng, M.Y. Multidirectional forging of AZ91 magnesium alloy and its effects on microstructures and mechanical properties. Mater. Sci. Eng. A 2015, 624, 157-168. [CrossRef]

6. Wang, Q.D.; Chen, Y.J.; Liu, M.P.; Lin, J.B.; Roven, H.J. Microstructure evolution of AZ series magnesium alloys during cyclic extrusion compression. Mater. Sci. Eng. A 2010, 527, 2265-2273. [CrossRef]

7. Al-Zubaydi, A.S.; Zhilyaev, A.P.; Wang, S.C.; Kucita, P.; Reed, P.A. Evolution of microstructure in AZ91 alloy processed by high-pressure torsion. J. Mater. Sci. 2016, 51, 3380-3389. [CrossRef]

8. Chung, C.W.; Ding, R.G.; Chiu, Y.L.; Gao, W. Effect of ECAP on microstructure and mechanical properties of cast AZ91 magnesium alloy. J. Phys. Conf. Ser. 2010, 241, 012101. [CrossRef]

9. Pérez-Prado, M.T.; Del Valle, J.A.; Ruano, O.A. Achieving high strength in commercial Mg cast alloys through large strain rolling. Mater. Lett. 2005, 59, 3299-3303. [CrossRef]

10. Feng, B.; Xin, Y.C.; Guo, F.L.; Yu, H.H.; Wu, Y.; Liu, Q. Compressive mechanical behavior of Al/Mg composite rods with different types of Al sleeve. Acta Mater. 2016, 120, 379-390. [CrossRef]

11. Segal, M.; Reznikov, V.I.; Drobyshevskiy, A.E.; Kopylov, V.I. Equal angular extrusion. Russ. Metal. 1981, 1, 99.

12. Liu, H.; Cheng, Z.J.; Yan, K.; Yan, J.L.; Bai, J.; Jiang, J.H.; Ma, A.B. Effect of multi-pass equal channel angular pressing on the microstructure and mechanical properties of a heterogeneous Mg88Y8Zn4 Alloy. J. Mater. Sci. Technol. 2016, 32, 1274-1281. [CrossRef]

13. Liu, H.; Ju, J.; Bai, J.; Sun, J.P.; Song, D.; Yan, J.L.; Jiang, J.H.; Ma, A.B. Preparation, microstructure evolutions, and mechanical property of an ultra-fine grained Mg-10Gd-4Y-1.5Zn-0.5Zr alloy. Metals 2017, 7, 398. [CrossRef]

14. Sun, J.P.; Yang, Z.Q.; Han, J.; Liu, H.; Song, D.; Jiang, J.H.; Ma, A.B. High strength and ductility AZ91 magnesium alloy with multi-heterogenous microstructures prepared by high-temperature ECAP and short-time aging. Mater. Sci. Eng. A 2018, 734, 485-490. [CrossRef] 
15. Valiev, R.Z.; Langdon, T.G. Principles of equal-channel angular pressing as a processing tool for grain refinement. Prog. Mater. Sci. 2006, 51, 881-981. [CrossRef]

16. Langdon, T.G. Twenty-five years of ultrafine-grained materials: Achieving exceptional properties through grain refinement. Acta Mater. 2013, 61, 7035-7059. [CrossRef]

17. Máthis, K.; Gubicza, J.; Nam, N.H. Microstructure and mechanical behavior of AZ91 Mg alloy processed by equal channel angular pressing. J. Alloys Compd. 2005, 394, 194-199. [CrossRef]

18. Zha, M.; Zhang, H.M.; Yu, Z.Y.; Zhang, X.H.; Meng, X.T.; Wang, H.Y.; Jiang, Q.C. Bimodal microstructure-A feasible strategy for high-strength and ductile metallic materials. J. Mater. Sci. Technol. 2018, 34, 257-264. [CrossRef]

19. Wang, H.Y.; Yu, Z.P.; Zhang, L.; Liu, C.G.; Zha, M.; Wang, C.; Jiang, Q.C. Achieving high strength and high ductility in magnesium alloy using hard-plate rolling (HPR) process. Sci. Rep. 2015, 5, 17100. [CrossRef] [PubMed]

20. Ma, A.B.; Nishida, Y.; Suzuki, K.; Shigematsu, I.; Saito, N. Characteristics of plastic deformation by rotary-die equal-channel angular pressing. Scr. Mater. 2005, 52, 433-437. [CrossRef]

21. Yuan, Y.C.; Ma, A.B.; Jiang, J.H.; Yang, D.H. Finite element analysis of the deformation distribution during Multi-Pass Rotary-Die ECAP. J. Mater. Eng. Perform. 2011, 20, 1378. [CrossRef]

22. Galiyev, A.; Kaibyshev, R.; Gottstein, G. Correlation of plastic deformation and dynamic recrystallization in magnesium alloy ZK60. Acta Mater. 2001, 49, 1199-1207. [CrossRef]

23. Robson, J.D.; Henry, D.T.; Davis, B. Particle effects on recrystallization in magnesium-manganese alloys: Particle-stimulated nucleation. Acta Mater. 2009, 57, 2739-2747. [CrossRef]

24. Liu, H.; Ju, J.; Yang, X.W.; Yan, J.L.; Song, D.; Jiang, J.H.; Ma, A.B. A two-step dynamic recrystallization induced by LPSO phases and its impact on mechanical property of severe plastic deformation processed Mg97Y2Zn1 alloy. J. Alloys Compd. 2017, 704, 509-517. [CrossRef]

25. Stepánek, R.; Pantelejev, L. Changes in mechanical properties of as-cast magnesium alloy az91 after equal channel angular pressing. Mater. Eng. 2015, 22, 160-165.

26. Ensafi, M.; Faraji, G.; Abdolvand, H. Cyclic extrusion compression angular pressing (CECAP) as a novel severe plastic deformation method for producing bulk ultrafine grained metals. Mater. Lett. 2017, 197, 12-16. [CrossRef]

27. Zhang, X.H.; Liu, X.J.; Wang, J.Z.; Cheng, Y.S. Effect of route on tensile anisotropy in equal channel angular pressing. Mater. Sci. Eng. A 2016, 676, 65-72. [CrossRef]

28. Chino, Y.; Mabuchi, M. Influences of grain size on mechanical properties of extruded AZ91 Mg alloy after different extrusion processes. Adv. Eng. Mater. 2001, 3, 981-983. [CrossRef]

29. Chuvil'Deev, V.N.; Nieh, T.G.; Gryaznov, M.Y.; Sysoev, A.N.; Kopylov, V.I. Low-temperature superplasticity and internal friction in microcrystalline Mg alloys processed by ECAP. Scr. Mater. 2004, 50, 861-865. [CrossRef]

30. Khani, S.; Aboutalebi, M.R.; Salehi, M.T.; Samim, H.R.; Palkowski, H. Microstructural development during equal channel angular pressing of as-cast AZ91 alloy. Mater. Sci. Eng. A 2016, 678, 44-56. [CrossRef]

31. Mabuchi, M.; Chino, Y.; Iwasaki, H. The grain size and texture dependence of tensile properties in extruded Mg-9Al-1Zn. Mater. Trans. 2001, 42, 1182-1189. [CrossRef]

32. Yuan, Y.C.; Ma, A.B.; Jiang, J.H.; Lu, F.M.; Jian, W.; Song, D.; Zhu, Y.T. Optimizing the strength and ductility of AZ91 Mg alloy by ECAP and subsequent aging. Mat. Sci. Eng. A 2013, 588, 329-334. [CrossRef]

33. Kim, W.J.; Park, J.D.; Kim, W.Y. Effect of differential speed rolling on microstructure and mechanical properties of an AZ91 magnesium alloy. J. Alloys Compd. 2008, 460, 289-293. [CrossRef]

34. Kim, W.J.; Hong, S.I.; Kim, Y.H. Enhancement of the strain hardening ability in ultrafine grained Mg alloys with high strength. Scr. Mater. 2012, 67, 689-692. [CrossRef]

35. Jiang, Y.B.; Guan, L.; Tang, G.Y.; Zhang, Z.H. Improved mechanical properties of Mg-9Al-1Zn alloy by the combination of aging, cold-rolling and electropulsing treatment. J. Alloys Compd. 2015, 626, 297-303. [CrossRef]

36. Zha, M.; Zhang, H.M.; Wang, C.; Wang, H.Y.; Zhang, E.B.; Jiang, Q.C. Prominent role of a high volume fraction of $\mathrm{Mg}_{17} \mathrm{Al}_{12}$ particles on tensile behaviors of rolled Mg-Al-Zn alloys. J. Alloys Compd. 2017, 728, 682-693. [CrossRef]

37. Zhang, J.S.; Zhang, W.B.; Bian, L.P.; Cheng, W.L.; Niu, X.F.; Xu, C.X.; Wu, S.J. Study of Mg-Gd-Zn-Zr alloys with long period stacking ordered structures. Mater. Sci. Eng. A 2013, 585, 268-276. [CrossRef] 
38. Garces, G.; Munoz-Morris, M.A.; Morris, D.G.; Perez, P.; Adeva, P. Optimization of strength by microstructural refinement of MgY2Zn1 alloy during extrusion and ECAP processing. Mater. Sci. Eng. A 2014, 614, 96-105. [CrossRef]

39. Chen, B.; Lu, C.; Lin, D.L.; Zeng, X.Q. Microstructural evolution and mechanical properties of Mg95.5Y3Zn1.5 alloy processed by extrusion and ECAP. Met. Mater. Int. 2014, 20, 285-290. [CrossRef]

40. Zhang, J.S.; Chen, C.J.; Cheng, W.L.; Bian, L.P.; Wang, H.X.; Xu, C.X. High-strength $\mathrm{Mg}_{93.96} \mathrm{Zn}_{2} \mathrm{Y}_{4} \mathrm{Sr}_{0.04}$ alloy with long-period stacking ordered structure. Mater. Sci. Eng. A 2013, 559, 416-420. [CrossRef]

41. Lu, F.M.; Ma, A.B.; Jiang, J.H.; Yang, D.H.; Yuan, Y.C.; Zhang, L.Y. Formation of profuse long period stacking ordered microcells in Mg-Gd-Zn-Zr alloy during multipass ECAP process. J. Alloys Compd. 2014, 601, 140-145. [CrossRef]

42. Yang, H.J.; An, X.H.; Shao, X.H.; Yang, X.M.; Li, S.X.; Wu, S.D.; Zhang, Z.F. Enhancing strength and ductility of Mg-12Gd-3Y-0.5Zr alloy by forming a bi-ultrafine microstructure. Mater. Sci. Eng. A 2011, 528, 4300-4311. [CrossRef]

43. Yan, K.; Bai, J.; Liu, H.; Jin, Z.Y. The precipitation behavior of $\mathrm{MgZn}_{2}$ and $\mathrm{Mg}_{4} \mathrm{Zn}_{7}$ phase in $\mathrm{Mg}-6 \mathrm{Zn}$ (wt.\%) alloy during equal-channel angular pressing. J. Magnes. Alloy. 2017, 5, 336-339. [CrossRef]

44. Yan, K.; Sun, Y.S.; Bai, J.; Xue, F. Microstructure and mechanical properties of ZA62 Mg alloy by equal-channel angular pressing. Mater. Sci. Eng. A 2011, 528, 1149-1153. [CrossRef]

45. Akbaripanah, F.; Fereshteh-Saniee, F.; Mahmudi, R.; Kim, H.K. Microstructural homogeneity, texture, tensile and shear behavior of AM60 magnesium alloy produced by extrusion and equal channel angular pressing. Mater. Des. 2013, 43, 31-39. [CrossRef]

46. Jin, L.; Lin, D.L.; Mao, D.L.; Zeng, X.Q.; Ding, W.J. Mechanical properties and microstructure of AZ31 Mg alloy processed by two-step equal channel angular extrusion. Mater. Lett. 2005, 59, 2267-2270. [CrossRef]

47. Gopi, K.R.; Nayaka, H.S.; Sahu, S. Investigation of microstructure and mechanical properties of ECAP-Processed AM series magnesium alloy. J. Mater. Eng. Perform. 2016, 25, 3737-3745. [CrossRef]

48. Cheng, W.L.; Tian, L.; Wang, H.X.; Bian, L.P.; Yu, H. Improved tensile properties of an equal channel angular pressed (ECAPed) Mg-8Sn-6Zn-2Al alloy by prior aging treatment. Mater. Sci. Eng. A 2017, 687, 148-154. [CrossRef]

49. Tang, L.L.; Zhao, Y.H.; Islamgaliev, R.K.; Tsao, C.Y.; Valiev, R.Z.; Lavernia, E.J.; Zhu, Y.T. Enhanced strength and ductility of AZ80 Mg alloys by spray forming and ECAP. Mater. Sci. Eng. A 2016, 670, 280-291. [CrossRef]

50. Wang, H.X.; Zhou, B.; Zhao, Y.T.; Zhou, K.K.; Cheng, W.L.; Liang, W. Effect of Si addition on the microstructure and mechanical properties of ECAPed Mg-15Al alloy. Mater. Sci. Eng. A 2014, 589, 119-124. [CrossRef]

51. Yuan, Y.C.; Ma, A.B.; Gou, X.F.; Jiang, J.H.; Arhin, G.; Song, D.; Liu, H. Effect of heat treatment and deformation temperature on the mechanical properties of ECAP processed ZK60 magnesium alloy. Mater. Sci. Eng. A 2016, 677, 125-132. [CrossRef]

52. Hansen, N. Hall-Petch relation and boundary strengthening. Scr. Mater. 2004, 51, 801-806. [CrossRef]

53. Yu, H.H.; Li, C.Z.; Xin, Y.C.; Chapuis, A.; Huang, X.X.; Liu, Q. The mechanism for the high dependence of the Hall-Petch slope for twinning/slip on texture in Mg alloys. Acta Mater. 2017, 128, 313-326. [CrossRef]

54. Wu, X.L.; Zhu, Y.T. Heterogeneous materials: A new class of materials with unprecedented mechanical properties. Mater. Res. Lett. 2017, 5, 527-532. [CrossRef]

(C) 2018 by the authors. Licensee MDPI, Basel, Switzerland. This article is an open access article distributed under the terms and conditions of the Creative Commons Attribution (CC BY) license (http:/ / creativecommons.org/licenses/by/4.0/). 